\title{
Structural restoration of an XVIIIth century building: the floor vaults of the Caserma "Principe Amedeo" in Nola
}

\author{
S. Voto ${ }^{1}$, M. Acanfora ${ }^{2} \&$ G. Manfredi ${ }^{1}$ \\ ${ }^{I}$ Department of Structural Analysis and Design, \\ University of Naples Federico II, Napoli, Italy \\ ${ }^{2}$ TRE Consortium, Napoli, Italy
}

\begin{abstract}
This paper presents the methodological approach for structurally restoring a highly damaged XVIIIth century building, the former military compound "Caserma Principe Amedeo", in view of its reutilization as House of Justice of the city of Nola, near Naples. The building was designed by one of the most important architects who operated in Naples at that time: Ferdinando Fuga. Today, its structure appears extremely damaged with many structural parts having collapsed and many others either statically unstable or close to collapse. In practice, this required reconstruction of the main façade, which was completely destroyed during WWII, and the rationale was to reproduce the same architecture as the original one, which implied an extensive and an in-depth historical investigation into the construction techniques of that period. This was particularly true for one of the main features of that construction, the building floor vaults, which were reconstructed following the design rules and the manufacturing techniques of the XVIIIth century in that area. This investigation made possible the re-design of an architectural layout that appears to be neat and functional to the future building utilization. It was possible to restore construction techniques applicable to materials and geometries perfectly correlated to the original design. This allows the reconstructed part of the building to smoothly fade into the architectural equilibrium of the original manufacture.

Keywords: historical masonry buildings, restoration, ancient techniques, vaults.
\end{abstract}




\section{The "Caserma Principe Amedeo" compound in Nola}

The Nola military compound was built between 1750 and 1756 during the reign of King Charles III of Bourbons. After taking power in 1743 over the new reign of Naples and Sicily, he implemented a defense military strategy based on the deployment of the entire Cavalry forces along the borders of the Reign, in order to quickly react to any outside danger. To overcome the shortage of lodging for the troops, around the year 1750 the King ordered the construction of "New stable quarters for lodging the Cavalry and the dragoons", in the cities of Nola, Nocera, Capua and Aversa. The local tradition that became consolidated with the years, considers Luigi Vanvitelli the architect of the Nola barracks. This thesis was defended in several publications issued between 1917 and 1950, but none of them resulted trustworthy under the filter of an accurate historical-critical investigation. Originally King Charles had assigned the work responsibility to military engineers, directed by Brigadier General G. Battista Bigotti. The original layout (1750-1754) was drawn by two military engineers; Agostino Caputo (the architect) and Giovanni Manzi (the construction work director). Since 1753 there has been a continuous alternance of new engineers assigned to overcome the construction mistakes that were introduced in the original construction. The recovery and completion of the construction were finally assigned to Ferdinando Fuga, a very famous architect active for the king of Naples at that time [1]. Fuga was involved for more than a decade on this task and at the end he left the unmistakable mark of his style in the construction of the Nola barracks. Though, not even the involvement of this Tuscanian architect managed to eliminate completely the original mistakes in the construction. In fact since 1818 further construction, to accomplish repair and fortification works, were decided on the military premises. Since 1840 arch. Gaetano Aulicino took charge with a project to complete the works definitely while reinforcing the older constructions that were giving signals of instability. On July 271846 “...all constructions making three sides of the compound were completed, the sheltering roofs as well,. still due a portion on the Northern side..." In the meantime it was prepared a layout of the barracks including "...dormitories on the right side, the House of the Trumpeters, the Music Room, the Cafeteria, the kitchens, dormitories on the left side, the Regiment room with the Pharmacy, the kitchen and the quarters for the non commissioned officers...". Once completed, the Nola compounds included also a huge drill ground, an open-air gallop and in the backspace a series of XIXth century design pavilions sheltered with wooden beamed roofs like the barracks. The building size is quite impressive, with four wings laid around a central open court. Its layout is based on a rectangular plan with an overall outside perimeter of $400 \mathrm{~m}$ (Fig. 1 and 2). After the achievement of the Unity of Italy (1861), the building was left abandoned up to 1872 . That year, boosted by discussions and protests, the War Ministry decided to lodge a regiment of the Italian Army Cavalry back in the barracks, asking the Nola Municipality a contribution up to $50 \%$ for the expenses for the stables and accessory rooms. But in 1875 the Regiment left the compound again "...for the bad conditions of the building that during its construction got weak foundations making necessary for several years frequent repairs...". Being Tommaso Vitale Mayor of Nola, the compound came back to new life and on 
October 21, 1881 the cavalry regiment came back (Figs. 3 and 4). Even though hosting a lazaret during the 1884 cholera epidemic, the military compound lived its best period up to the beginning of the XXth century. In 1887 the Ferdinando Maiorano of Nola described the compound "....with a rectangular shape, very wide longitudinal stables on the ground floor, four meter wide arcades on the ground floor, the first and second storey as well, a vast court with two wells in the corners, troughs for the horses, wide climbing stairs, but what makes it particularly useful is the very large drill ground, with a surface of $70.000 \mathrm{~m}^{2}$, on the western side...". On November 27 and December 1, 1889 the "Caserma Nuova" was visited by Prince Amedeo of Aosta, that inspected the 9th Regiment "Lancieri Firenze". A plaque on the main entry was remembering that visit since June 24, 1904 and the barracks were named "Caserma Principe Amedeo". The compound remained in operation as military barracks up to September 1943. At that time, the barracks were mined and extensively damaged by the German troops beating their retreat from the Naples area. Since then the building was not used for military scopes any more: the building was partially reconstructed and restored around 1972, to host judicial offices and a school, but the main façade remained in its collapsed and disrupted shape since.

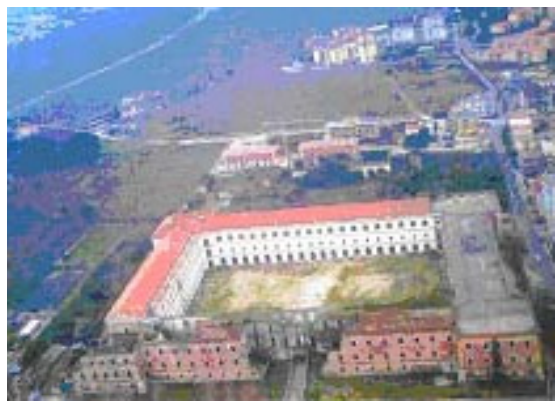

Figure 1:

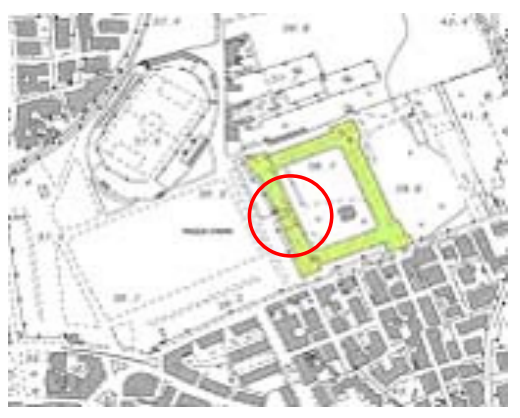

Figure 2:

Plan view - area of intervention.

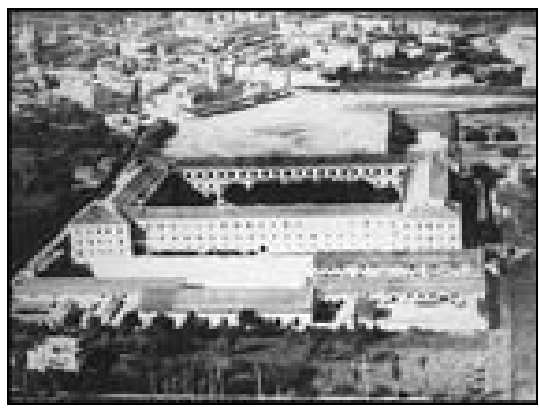

Figure 3: Nola, Caserma Principe Amedeo and drill ground.

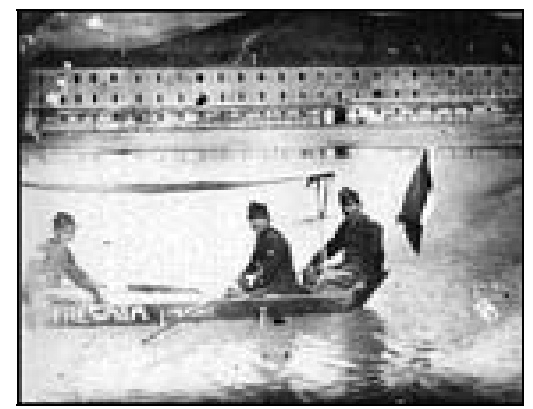

Figure 4: Water military games in the flooded frontal drill ground. 


\section{Typological analysis of existing vaulted structures}

While beating their retreat from Southern Italy, during the Second World War, the German troops tried to hinder the movements of the allied troops mining several buildings, among which the City Hall, the Military District (former Orsini Royal Palace) and the "Caserma Principe Amedeo" compound. The main façade of this building was extensively damaged and spoiled, with the total destruction of the beautiful entry portal in white marble (Fig. 5).

The structure to be restored is now limited to $45 \mathrm{~m}$ (Fig. 2) of the front side across the main entry gate. The restoration work is aimed at reconstructing this central part of the building, reproducing the vaulted floor with the same techniques and same materials as the original ones.

From a structural point of view several problems were considered in the design process. Aspects to be evaluated were associated with the level of decay caused by the environmental actions and man-made disruptions in correspondence of the collapsed structures such as:

- Reconstruction of the collapsed portions of the structure with similar techniques and technologies used as the original ones;

- Retrofitting of the structural parts that didn't collapse, but suffer a poor stability condition;

- Connection between the reconstructed part of the structure and the ones still in place;

- Verification of the structural safety of vertical loads and seismic actions.

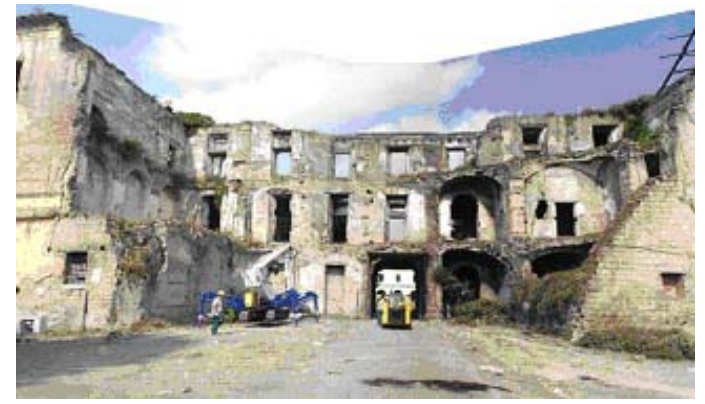

Figure 5: $\quad$ Front view of the intervention area.

It was necessary to inter-correlate all these problems in order to design a structural restoration that guaranteed the architectural original equilibrium of the building.

Prior to the restoration work, it was necessary to run a typological analysis on the existing vaults of the building (Fig. 6 and 7).

On one side this analysis allowed to understand the construction architecture of each single vaulted element, with reference to the geometrical, dimensional and constructional characteristics. On the other hand it was necessary to understand the relationship between the single vaulted element and the spatial organisation and constructional rationale of the global architectural organism. 
The first phase of the research was focused on finding and analysing the bibliographical sources of reference. Reading and studying manuals and historical treatises was associated to the observation and analysis on the spot of the vaults still existing in the remaining portion of the building. According to the ancient construction practice the distribution of vaulted floors required a distribution of masses strictly correlated to the resolution of the problem of pushing forces in filling and designing the space [2].

The mass distribution and geometry were conceived following tight rules based on modular baseline elements of the whole architectural organism.

To reach the equilibrium, the constructional solutions could not be randomly distributed, but were following constructional typological models that were coded according to the single structural parts and to the relationships existing within the structural components [3].

The investigation on the vaults of the Nola Barracks allowed one to conclude that they are a particular derivation of the classical spherical ribbed vault [4].

When there is not enough room to accommodate spherical vaults, the ribbed vault becomes the only alternative.

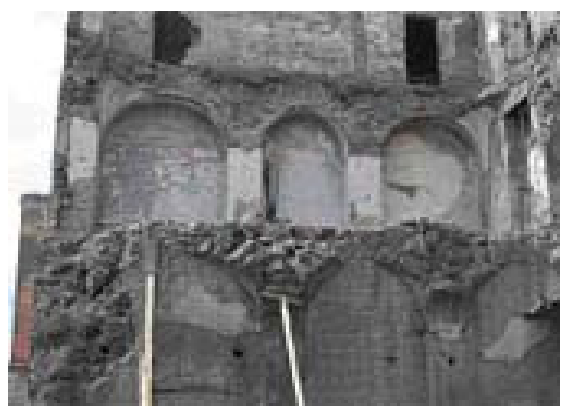

Figure 6: Overall view collapsed vaults.

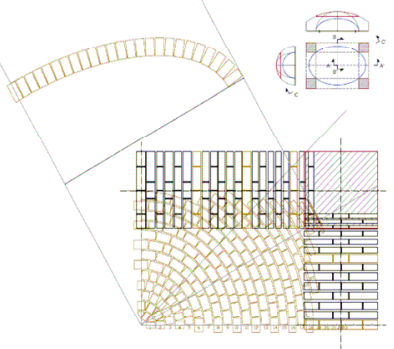

Figure 8: Geometric layout of Figure 9: the ellipsoidal vault.

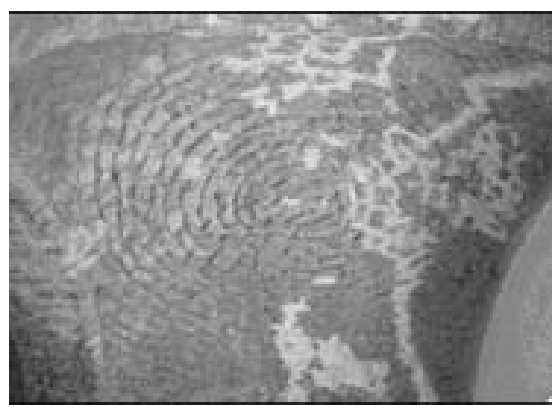

of Figure 7:

General view of the existing vault.

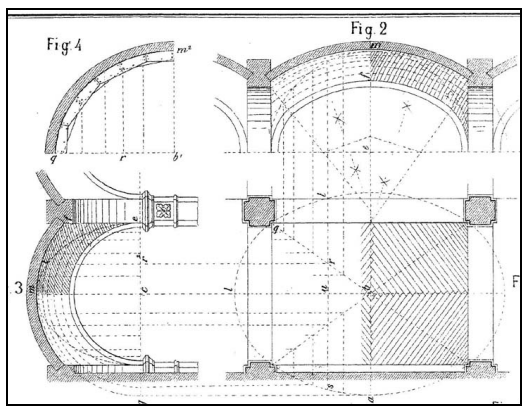

The geometric scheme of the "bohemian copes" vault (G.A. Breymann). 
This surface is generated defining some reference lines accordingly to the available room and available heights and moving them along the generant lines. In the Nola building the vaulted surface generating element is an ellipse [5]. Fig. 8 shows a plan view of such a type of vault. Imposing the conditions that the supporting arches of a vault with rectangular plan section maintain their highest points at the same height, the arches standing on the longer side of the rectangle becomes ellipses, the vault surface becomes a rotational ellipsoid and its axis becomes coincident with the longitudinal axis of the rectangle. This particular vault shape is named "bohemian copes" [6] and it is an ellipsoidical ribbed vault with depressed arches (Fig. 9).

\section{Reconstruction of the vaults}

The historical investigation allowed to define the different constructional phases to be followed for the construction of this type of vault. The main vertical structures of the building are made of striped tuff masonry; the secondary padding structures are characterized by faced walls. The horizontal structures are mainly realized with tuff masonry vaults, with the bricks aligned with their length parallel to the vertical direction for the first two planks. It was felt worth to build, in the open space in front of the main façade, a pilot vault before starting the restoration work to practice the ancient fabrication techniques and demonstrate the structural reliability of the reconstructed vault. The vault discharge the vertical loads on the corner pillars through the interposition of arches armed between those pillars. Normally the arch is set up on both sides starting from the masonry piers (shoulders), through the installation of a first masonry element named impost ashlar or dosseret [7]. The construction is continued setting up wedged ashlars starting from the side imposts and moving towards the central portion of the arch that was completed with a specific element (key stone) that stabilizes the structure [8]. To arm the arch and the vault, it is necessary to sustain its wedged ashlars up to the positioning of the key stone, that guarantees the equilibrium of the whole structure. So during construction there is the need of a provisional structure, a rib, allowing the positioning of the bricks. The average strength of the masonry was assumed to be $30 \mathrm{daN} / \mathrm{cm}^{2}$, in compliance with the results of the experimental investigations that correlated the information on mechanical strength of in situ masonry (i.e. 30 $\mathrm{daN} / \mathrm{cm}^{2}$ ) with the mechanical property of single bricks as determined in the laboratory (average value was greater than $40 \mathrm{daN} / \mathrm{cm}^{2}$. The masonry vault is 40 $\mathrm{cm}$ thick and discharges on four arches with a span of 2,6 $\mathrm{m}$ for the shorter up to $4,6 \mathrm{~m}$ for the longer side. To verify the correct behaviour of the new vaults to be built, a load test was performed on the full scale pilot vault. Once accomplished the fabrication of the four pillars of the pilot vault, the sustaining ribs were put in place for the construction of the four large arches on which the vault must discharge. Once the four columns were built, the formwork were put in place for the construction of the four large arches sustaining the vault.

For the existing structure, the discharging arches were built disposing a first row of stones laid up by the flat side, followed by a jack flatted one. During their 
reconstruction (two ellipsoidical and two circular) the authors preferred to alternate the diatones to the orthostaticals to guarantee a better teething between the two layers (Fig. 10 and 11). In the reconstruction of the pillars for the dimension of the base brick the authors referred to the ones found in the existing structure, using stones with dimensions commonly used in the past, with a size that was half or three quarters of the base stone.

The rows of bricks of the existing vaults were distributed like the parallels of the spherical intrados (Fig. 12 and 13), realizing several rings filled with mortars; the vertex of these truncated cone shaped rings is located in the centre of the vault. In the upper part of the vault it was not possible to build too small rings and the vault was closed with rows with opposite inclinations, parallel to the two diagonal meridian lines.
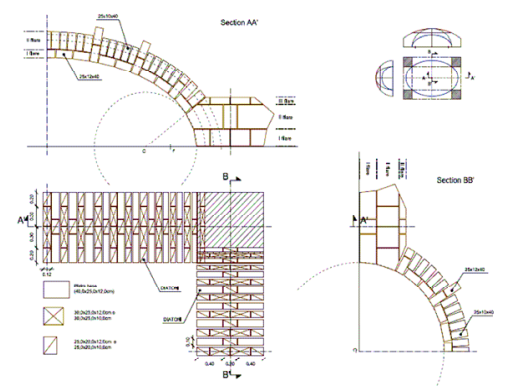

Figure 10: Plan view and section of the pilot vault arches.

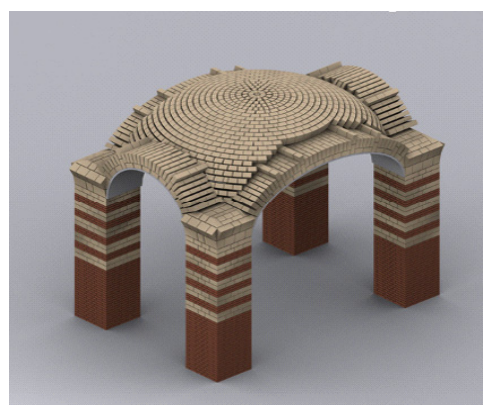

Figure 12: CAD Model of the vault.

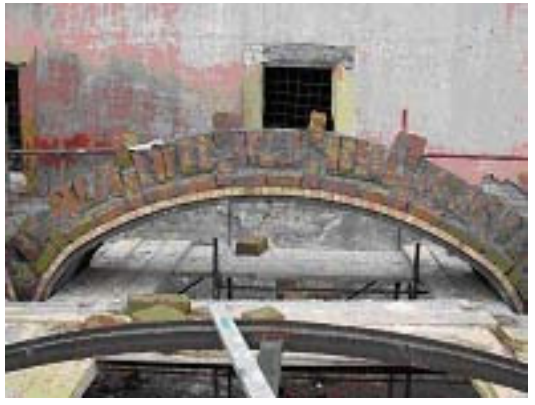

Figure 11: $\quad$ Rows of the elliptical arch.

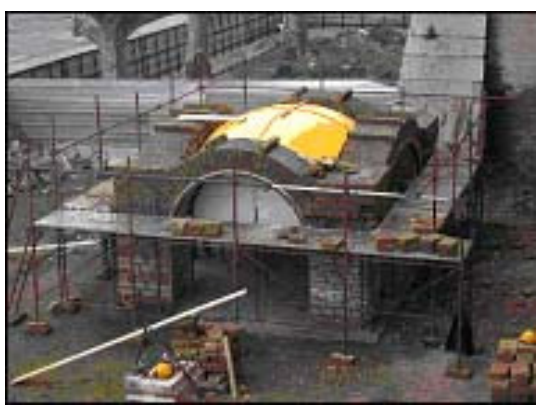

Figure 13: The brick sustaining rib.

\section{The vault timbering}

In the reconstruction of the vaults a particular attention was paid to the coomb for the vault timbering, since there were no prefabricated coombs available on the shelf that could match the specific geometry of the existing vaults. It was necessary to fabricate a suitable coomb that on one hand allowed to reintroduce 
the ancient techniques for the timbering and construction of those vaults, on the other one would limit significantly the fabrication costs. Based on the dimensions of an existing vault it was fabricated a polymeric preform (polystyrene coated with a film of polyvinyl chloride) perfectly following the ellipsoidal shape of the vault. The coomb was fabricated through utilization of a numerical control machine with a part program giving the mathematical model of an existing vault geometry. The vaults to be reconstructed have different dimensions. Consequently the preform coomb was made in four sectors mating along the two axis of symmetry. This way it was possible to adjust the coomb to all different existing geometries. The polyvinyl film coating was introduced to get a smooth surface easy to disassemble once built the vault (Fig. 14). Once fabricated the arches and installed the coombs, the ellipsoidal caps were realized as for the pilot vault (Fig. 15).

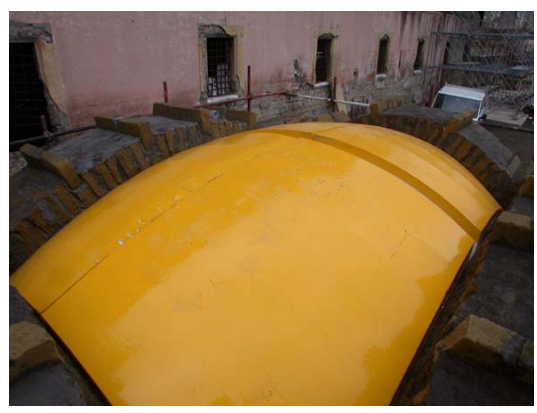

Figure 14: Vault coomb.

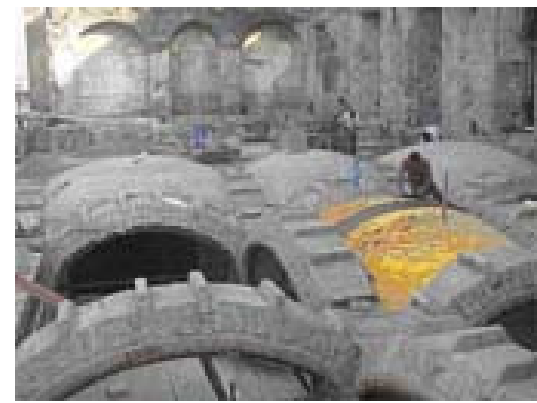

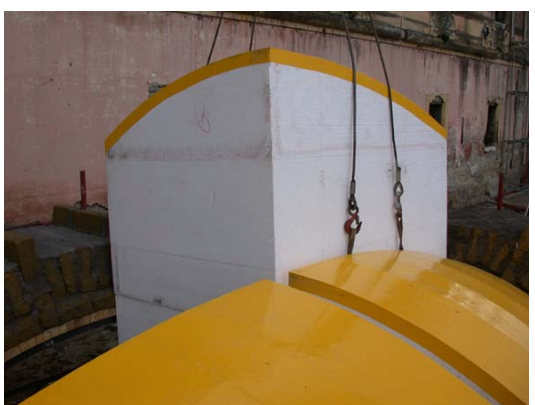

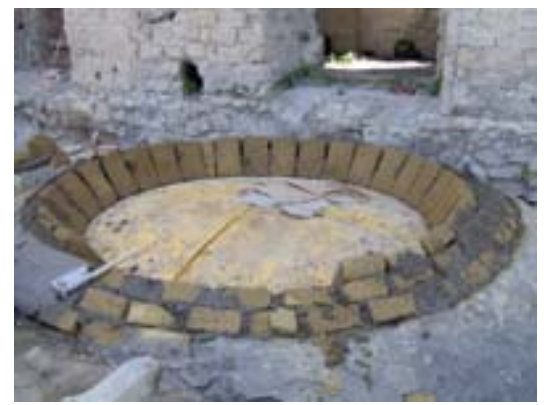

Figure 15: Ongoing construction.

\section{Structural verification of the vault behaviour}

A flat horizontal surface was realized on the top of the test pilot vault using incoherent shrinkage-free mortar. Four scarp walls were built to simulate the counter- pushing loads of the adjacent vaults during the test (Fig. 16). The structural behaviour of the vault was analysed focusing the attention on its 
constituting elements and investigating the displacement of each one of them: the displacements of the cap, of the four discharging arches and of the four pillars. were monitored. The structure behaved in an elastic fashion returning completely its deformation after releasing the test load. The test on the pilot vault was conducted up to the design test load of $600 \mathrm{daN} / \mathrm{mm}^{2}$; and then increasing the load up to $1200 \mathrm{daN} / \mathrm{mm}^{2}$, almost twice as much as the design load. The structure response was positive and the test data were in line with the value of the predictive analysis. The test was run loading progressively the extrados surface filling a 4,00×5,00 x1,25 m pool with water. Eight displacement readings were made at different loading values, starting from the condition of the vault loaded by its own weight only. Vertical displacements of specific points defined at the intrados of the vault, located close to the keystone and the foot of the arches, were measured using thirteen mechanical centesimal gauges positioned on telescopic bar standing vertically to react between the structure and the foundation mat . A topographic survey was used also to measure the horizontal displacement of the arch keystone in a direction orthogonal to its plane and to evaluate the dimensional variation of the span between the feet of the arch. Bimillesimal mechanical deformometers were used to evaluate the axial displacement of the columns. A linear model was used to evaluate the highly complex behaviour of the structure under loads much smaller than the actual system capacity (service loads) as per Fig. 17. The pressure curve for each element (main arch, vault, etc.) was determined starting from the actual load distribution. A failure analysis of the vault was made with a variable model (more and more less hyperstatic) up to reaching the onset of a mechanism in correspondence of which the structure collapses, being practically weak. The analysis defines a maximum collapsing load of about $36 \mathrm{kN} / \mathrm{m}^{2}$. A nonlinear predictive model of the vault was made under the same hypothesis as the failure load analysis, with reference to the geometry and mechanical characteristics of the materials. The achieved result confirm the extremely brittle behavior of such systems with a linear trend up to failure in correspondence of a load of about $40 \mathrm{kN} / \mathrm{m}^{2}$. The two analysis methods yield similar results, since there is only a $10 \%$ difference.

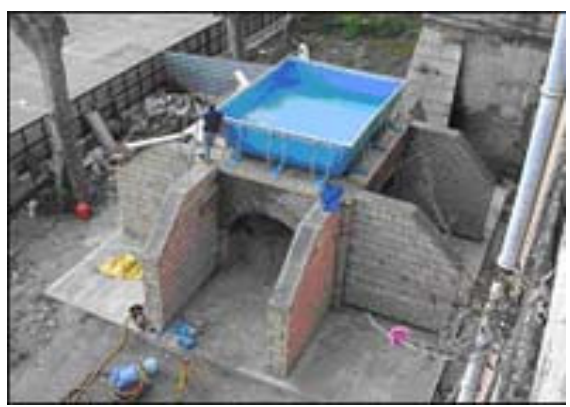

Figure 16: Top view of the water pool.

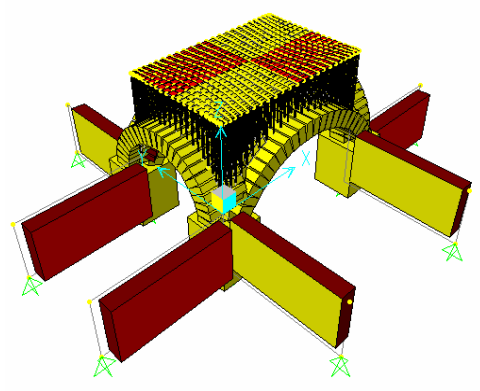

predictive model. 
From the load test the following conclusions can be drawn:

- Horizontal out of plane displacements were practically non-existing (order of magnitude cent of millimeter);

- Crack pattern under the test load was practically non-existing;

- Maximum vertical displacement of the vault keystone was only $0,5 \mathrm{~mm}$ below the overall maximum load determined by analysis;

- Structure behaviour was almost linear, up to the maximum load that was

- considered $\left(12 \mathrm{kN} / \mathrm{m}^{2}\right)$

\section{Conclusion}

The reconstruction of the front façade was launched, and is now in an advanced stage of accomplishment. The restored structures being rebuilt is distinguished from the original one but perfectly fade into the original architectural configuration, satisfying the rationale of being fully respectful of the ancient building fingerprinting main characters. Figs 18-20 show some images of the vaults at the first storey after being fabricated.

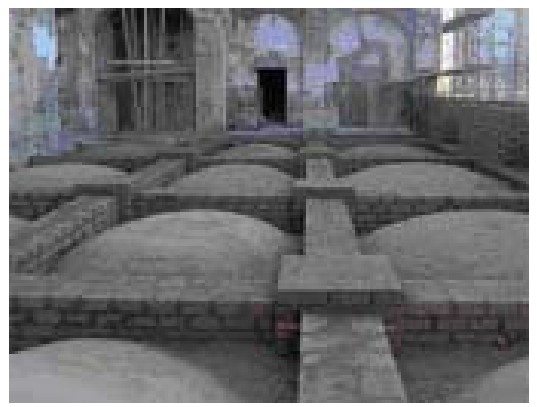

Figure 18: View of the vault extrados.
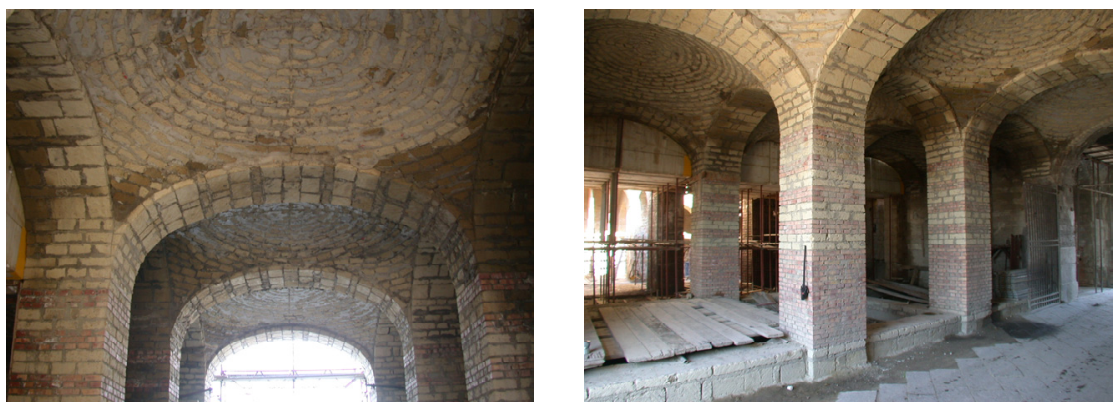

Figure 20: General view of the vault intrados. 


\section{References}

[1] Nunzianta Matilde, La Caserma Principe Amedeo e le altre Caserme borboniche, a cura dei Maestri di Festa Barca, Nola, 1995

[2] Acocella Alfonso, Architettura di pietra - Antichi e nuovi magisteri costruttivi, Lucense Alinea, Città di Castello (Perugia), 2004

[3] Abbate F., Sollecitazione e forma - La forma delle strutture, Edizione Cuen, Napoli, 1997

[4] Rondelet Giovanni, Trattato teorico e pratico dell'arte di edificare, prima traduzione italiana della VI ed. originale, Mantova, 1834

[5] Costruzioni in pietra, casa editrice Dottor Francesco Vallardi Milano, 1884

[6] G. A. Breymann, Trattato generale di Costruzioni Civili con cenni speciali alle costruzioni grandiose

[7] Formenti C., La pratica del fabbricare, Milano Hoepli, 1993

[8] Erminia Attaianese, Vittorio Fiore, Maria Rita Pinto, Serena Viola, La costruzione tradizionale, note sulle tecniche costruttive nel napoletano, de Costanzo Editori, Napoli 1993 